\title{
NEW GEOLOGIC MAP OF THE POINT SUR 30’X60' QUADRANGLE, A TRIBUTE TO LEW ROSENBERG
}

C.J. Wills

California Geological Survey, Sacramento CA, 95814, chris.wills@conservation.ca.gov

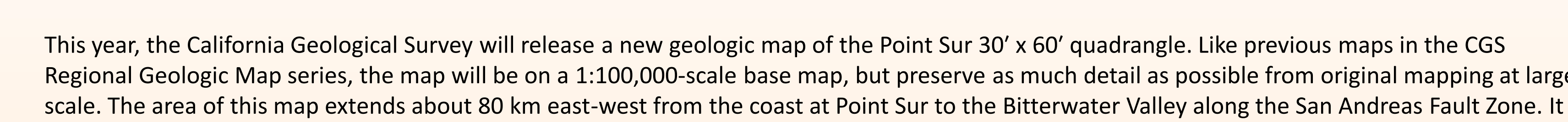

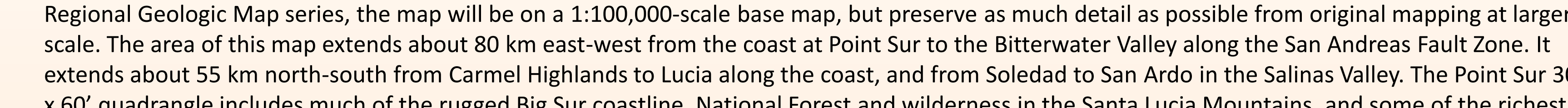

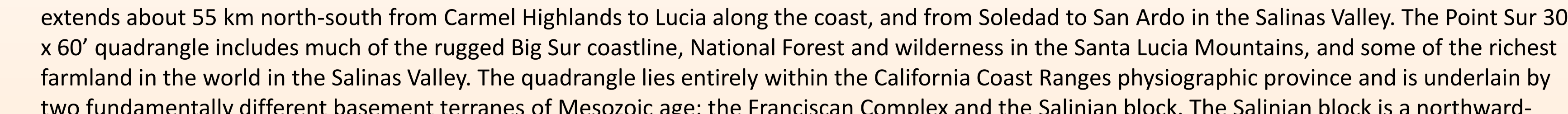

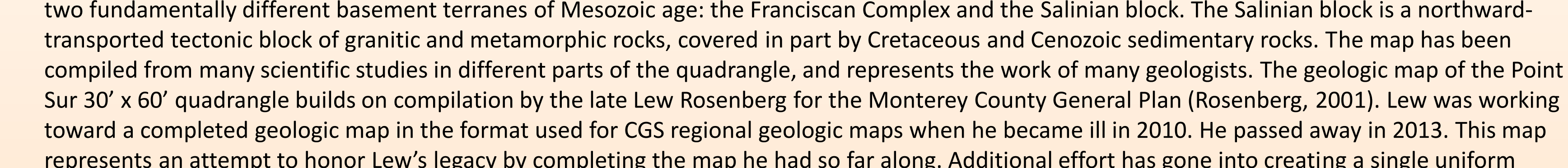

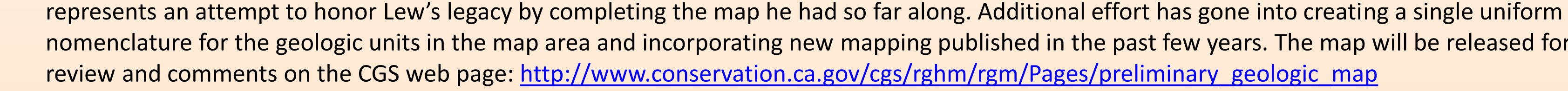
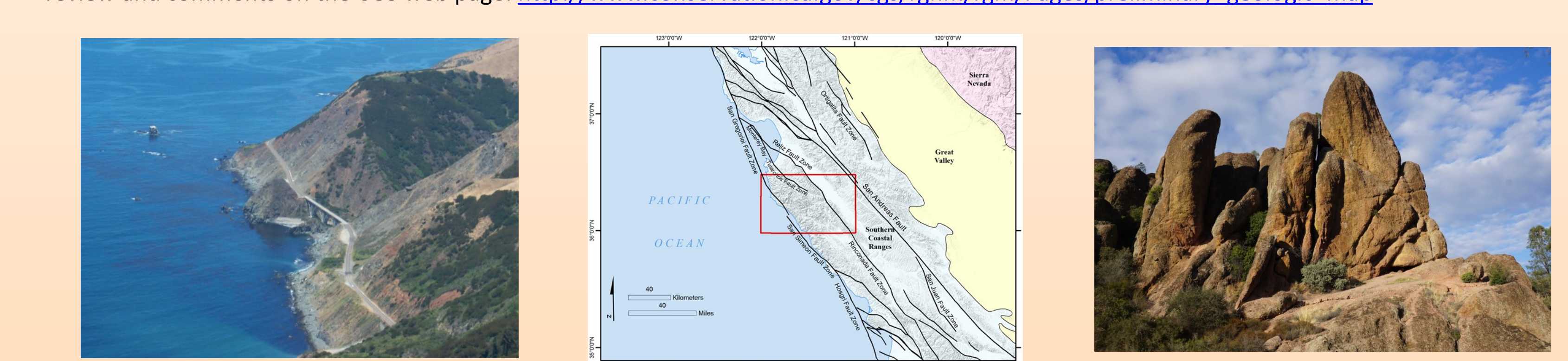

Mapping compiled for the Point Sur $30^{\prime} \times 60^{\prime}$ quadrangle includes bedrock mapping by Hall (1991) augmented by mapping of Quaternary units by Wills et al. (2001) along the Big Sur coast and the details of the Pinnacles volcanic center by Matthews (1971). Quatererary
(1975) and Taylor and Sweetkind (2014).

$$
4
$$
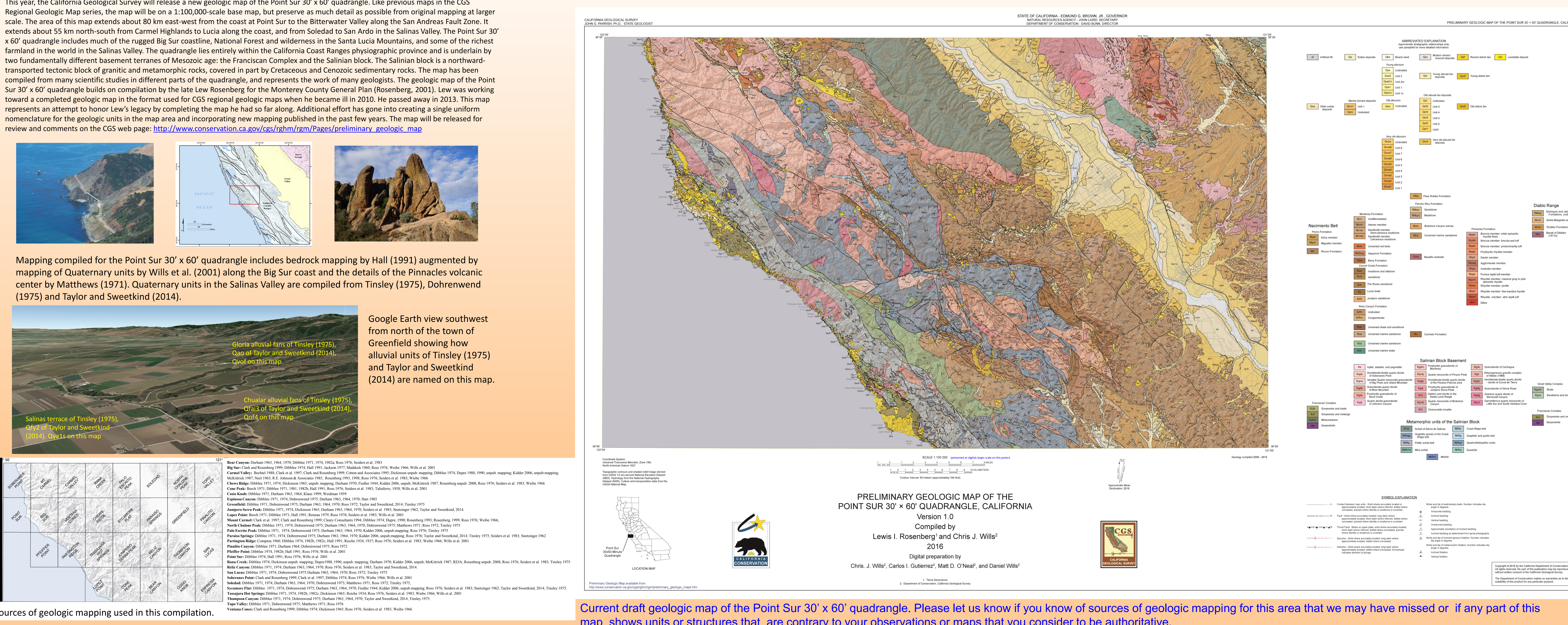
Current draft geologic map of the Point Sur $30^{\prime} \times 60^{\prime}$ quadrangle. Please let us know if you know of sources of geologic mapping for this area that we may have missed or if any part of this
map shows units or structures that are contrary to your observations or maps that you consider to be authoritative.

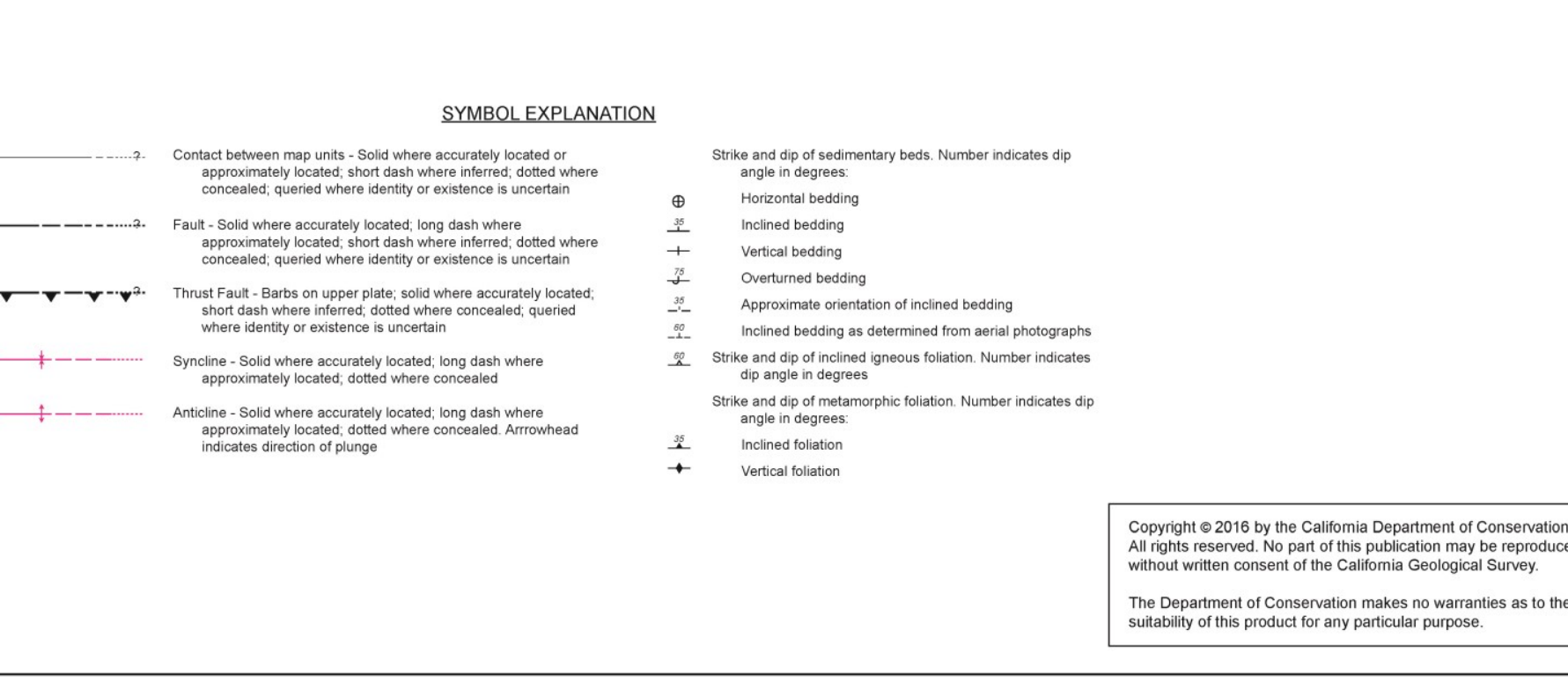

